\title{
Ritual and Ritualism in a Contested Sea: Scalar Distortions of Space and Time
}

\author{
Michael Herzfeld
}

\begin{abstract}
The ground of mutual understanding between locals and migrants in the Mediterranean Sea emerges through the performance of ritual activities. These should be distinguished from the formalistic or incantatory sense of "ritualism." They include the socially engaged practices of hospitality - a virtuous tradition that governments, even as they claim it for the nation-state, violate in local eyes by confining migrants to impersonal spaces and uncertain futures. Passages across the sea also partake of a pervasive sense of ritual, which thereby offers rich metaphorical material for considering the scalar shifts at play-shifts that entrain such conversions of social interaction into the asocial frameworks of neoliberal management (which in turn encourage aridly scientistic modes of inquiry) but conversely also domesticate cultural distance through a subtle apperception of shared habits of gesture and generosity, made accessible by the close vision of ethnography as described in these essays.
\end{abstract}

\footnotetext{
M. Herzfeld $(\bowtie)$

Harvard University, Cambridge, MA, USA

Leiden University, Leiden, Netherlands

University of Melbourne, Parkville, VIC, Australia

Shanghai International Studies University, Shanghai, China

e-mail: herzfeld@fas.harvard.edu

(C) The Author(s) 2021

V. Grotti, M. Brightman (eds.), Migrant Hospitalities in the Mediterranean, https://doi.org/10.1007/978-3-030-56585-5_5
} 
Keywords Ritualism $\bullet$ Rites of passage $\bullet$ Sea $\bullet$ Scale $\bullet$ Language $\bullet$ Gesture • Hospitality

Anthropologists are thankfully long past the era of wondering whether one could talk about a "Mediterranean culture." By and large, they have realized, and accepted, that what is interesting is not what anthropologists have to say about this topic but what people who live in the area claim and what they do about it. If doctors and dieticians wax ecstatic about something called the "Mediterranean diet," if political leaders invoke something vaguely conceptualized as a common Mediterranean heritage, if local people invoke a supposed similarity between themselves and the neighboring countries, it matters not a whit that others might find many of those claims contrived or even specious. What matters is that social actors, invested with varying degrees of power and authority, not only utter them but also often deploy them for clearly material ends. Moreover, they do so with a ritualism, an incantatory solemnity, that for anthropologists demands analytical attention rather than acquiescence in an official version of self-stereotyping, an acquiescence that leads to "methodological nationalism" on the grand scale.

In these observations, largely written in response to the other essays in this volume, I am going to explore that ritualism on its own terms. Taking my cue from Edwin Ardener's sensible rhetorical question, "When is a rite not of passage?," I propose to see how far Arnold van Gennep's classic formulation can be used to show how local people and anthropologists alike depend on rituals of belonging and learning to make sense of today's wildly roiling sea and how the common structure of their perceptions may help us refine our methods while also strengthening the role of ethnography in the study of processes that for too long have been the privileged domain of self-appointed experts with little experience-based knowledge of the region or preparation for working within it.

In framing my argument in this way, I am instantiating the theoretical point that comparison is not only compatible with a reflexive stance but is also necessarily part and parcel of what such a stance entails. One cannot realistically compare social and cultural worlds except through the personal experience of traversing difference, whether in the mind or, perhaps preferably, by switching field contexts; and one's self-knowledge is itself the product of such deliberately discommoding experiences, such selfinflicted ruptures of normality and routine. Anthropologists are rarely still, 
and their movements through time and space produce a constant stream of comparative observations, which often start out as self-inflicted culture shock before they mature into scholarly reflections.

Before I go any further, I would like to separate two very similar words from each other: ritual and ritualism. Rituals, or rites, are events, acts of piety or supplication, and they mark individuals' ties to a social context that they more or less understand as their own. These terms have implications, variable though they may be in scope and intensity, of belonging to that context. Ritualism, by contrast, is (as the suffix implies in the original Greek), an imitation of ritual, an invocation of form in which the claim on participants' affective loyalty may be presumptive or coercive but in any case cannot be assumed to be genuinely efficacious. It is, to invoke an old American political phrase, a claim on "hearts and minds" that presumes to judge participants, not for their personal sense of commitment but for their outward displays of conformity. Like scientism in relation to science, or moralism to morals, ritualism is a rhetorical appropriation of a socially relevant practice for political or ideological purposes. The distinction is not an absolute one, since individuals may take part in a local ritual without any sense of commitment or belief-simply "going through the motions"-but I would consider such an act to be ritualistic rather than a genuine practice of ritual. Like everything else in the nation-state, ritualism does, after all, also have social roots.

We might then see ritual as a model for the ritualism of bureaucracy with which I will be concerned later in this essay. Rituals are stretched into ritualism when they are conducted on a massive scale because the sheer difference of scale makes any sense of intimate participation untenable. But ritual as metaphor does not only serve the mechanistic purposes of a nation-state bureaucracy. It may also serve as a powerful literary device for calibrating individual experience with social life, in much the same way that actual rites perform the realignment of individuals and groups with the societies of which they are members or into which they are inducted.

Claude Lévi-Strauss was perhaps the first to realize the literary potential of ritual as metaphor when, in Tristes Tropiques, he invoked images of ritual passage every time he crossed a sea, a continent, or a national boundary, or, indeed, when he crossed from one stage in his life to another. ${ }^{2}$ Like many of the migrants in today's Mediterranean, although under notably more comfortable conditions, he was a refugee from violence and the threat of annihilation - in his case, that posed to anyone of Jewish origin by the pro-Nazi Vichy regime in France. Tristes Tropiques is a tale of 
crossings. In traversing tropics, Lévi-Strauss invoked a tropology; in traversing topics, he metaphorized a conceptual topology. Tristes Tropiques is a poetic masterpiece, but, as has often been observed, it is not ethnography. It is, rather, and more importantly, a prologue and an exhortation to a more self-conscious ethnographic practice and an early precursor of the idea that reflexivity and comparison are part of the same determinedly rooted experiential practice that we call ethnography-a practice that requires, in a word, passage: passage through a temporally defined learning curve, spatial passage from one site of knowledge to another. ${ }^{3}$

Naor Ben-Yehoyada's The Mediterranean Incarnate illustrates this passage ethnographically and textually. ${ }^{4}$ The book crosses many frontiers, notably in the gripping scenes of passage across the sea as the exhausted ethnographer cooks for his Tunisian fellow-sailors on a Sicilian boat, catches his share of watch duty, photographs every detail he can capture, and struggles to maintain his note-taking. This shipboard initiation was a rite of passage in multiple senses, including that of producing a doctoral dissertation and rethinking it as a book. In that sense, all anthropologists undergo similar forms of passage. In this case, what emerges is not a static cultural area but, in its place, an encompassing cultural debate carried on by the warring (and occasionally peacemaking) peoples of the region over millennia of interaction and producing the relationship that he aptly identifies as cousinage rather than siblinghood.

Migrants themselves often conceive their experiences as analogous to ritual passage. This should not surprise us; the power of passage as a metaphor comes from its capacity to link different kinds of ritual experiencemarriage and death in Greek rural rituals, for example, and the funereal experience of exile among Albanian migrants so lugubriously described in the poem that Vanessa Grotti and Marc Brightman use as the epigram for their essay. Senegalese Mouride workers in Turin treat their wanderings like the hajj to Mecca, as do Turkish migrants in Europe their regular return visits to their home communities. ${ }^{5}$

People have thus been wandering across differences of scale-this is itself a powerful moment of intellectual passage for our discipline-in many places and epochs; and many of the experiences of passage are about the search for a better life. The very language of progress and development, concepts redolent of the evolutionist thinking of a resurgent colonialist impulse, builds on the same implication that people should seek the means of improvement through the spatiotemporal framework of passage. Ardener's question, which was presumably intended to ask critically what 
value such a teleological model as van Gennep's could have, can be transformed through another scalar shift into a demand to know how any crossing of the dangerous sea could ever be undertaken without hopes of passing to a new and better life.

But nothing, for the migrants or for ethnographers, is certain at the outset. Ritual-notably as transition-entails risk, as van Gennep's successors Mary Douglas and Victor Turner both recognized. ${ }^{6}$ Are these ritual pilgrimages usually destined to lead to disappointment, or can the harried migrant and the ambitious ethnographer expect them to lead to some identifiable success? For the ethnographer, member of a privileged elite that can even transform a tale of failure into a literary triumph, ${ }^{7}$ the risks are perhaps slight. For the migrants, however, they are enormous. There are so many stories, for example, of women lured into prostitution with promises of a glamorous new life, who ultimately find themselves desperate to escape back to the relative safety and dignity of poverty at homewhere, however, they may also face opprobrium (or worse) for their sexual misadventures or for their failure to bring home new wealth. Scaling up from the comfort of familiar rituals to the terror of passage into the vast unknown seems, more often than not, a path to disaster.

Metaphors are by their very nature open to variable and unpredictable interpretation. They can be cannily manipulated and grievously misunderstood. Scaling up is one process that exposes their fragility. Recontextualizing them is another. Fighting fire with fire, I propose here to re-deploy the metaphor of the rite of passage as a means of exposing, together with the other authors in this collection, the structural violence that has lurked behind claims of sovereignty and stability. This is a matter that also affects the practice of our discipline, which itself is partially entrapped in the logics of various nation-states' adaptations of neoliberalism and audit culture to the largely inappropriate domain of academic life.

The highly domestic methodology of ethnography is a striking example of this problem. It faces a similar scalar shift of application to those documented in this volume and faces similar (if nevertheless far less lifethreatening) threats in consequence. In this regard, it resembles the equally domestic practice of hospitality, on which, moreover, it is deeply dependent. Insofar as anthropologists do their research as guests of those whose lives they study, they necessarily also experience the tension between kindly care and the exercise of careful control over the stranger that is at the heart of hospitality, especially in those many Mediterranean lands in which it has become the basis of claims to both radical similarity and, as 
"national character," equally radical distinctiveness. Ethnography's confinement to the level of local research now exposes it to charges of triviality and marginality, conveniently, one should note, for the more surveyoriented and top-down disciplines that might be discommoded by the data that ethnographic research unearths.

In this industrial and neoliberal age, an age that has not yet dispensed with the territorial obsessions of nationalism, hospitality has also become the operative metaphor for scalar inflation ranging from the hotel and catering industry to the reception of migrants and even incarceration. Lacking the grim irony of the British idiom of being "guests of Her Majesty," the most coercive versions of these inflated hospitalities are softened only by the agency of specific individuals, disgusted by what they are asked to do to their fellow human beings and prepared to risk the wrath of their superiors in order not to violate their own understanding of what hospitality entails - the duties of the host, violated by those who allow the control side of hospitality to outweigh the caring dimension to the point at which the ritual politeness is swept aside by the cruel realities of imprisonment and death.

And death itself calls for rites of passage; when the rituals of death are not consummated for the visitor unfortunate enough to have died far from home, one of the fundamental principles of hospitality is violated. Such a breakdown demands a critical inspection of the ways in which different kinds of passage merge in a combustible mixture that, instead of producing gratitude and reciprocal kindness, triggers outrage, warfare, repudiation of commonality, and the breakdown of that common humanity Greeks call anthropiá. Inasmuch as friendship and hospitality can morph into each other with frightening ease even beyond the ritualized transitions that I have reported from mountainous western Crete, for example, and that are especially true for the segmentary tribal structures of Bedouin-based polities in Jordan, Saudi Arabia, and elsewhere in the Arab world, they operate like the equally tensile binary of peace and genocide noted by Kapferer in the Buddhist world. ${ }^{8}$

Given the way in which hospitality combines lateral generosity with vertical power plays, it is an ideal site for just such abrupt transformations. While it is an enactment of reciprocal ethical obligations, the travesties that its projection onto larger scales has produced expose a tension between those obligations and the bureaucratic desire for control. It is here that "upscaling" threatens the ideals of generosity that the ostensible ideology of hospitality promotes. The essays in this volume complicate this 
sad picture, showing how even within the most hostile environment some social actors make it their business to reclaim the space of hospitality for what they consider to be its rightful ethical use. It is interesting to read in Grotti and Brightman's essay that a politician like Martello, despite his participation in a national government that took a decidedly tough line on immigration, may nevertheless, operating in a local setting with intensified significance in the national debates on the topic, invoke hospitality to call attention to the failures of the new, right-wing government to be good hosts. His move was plainly political; equally plain, however, was the ethical appeal at its core-an ethics grounded in ideals of hospitality and reciprocity.

Mention of ethics, moreover, also requires consideration of what it is that anthropologists do differently from other social science disciplines, especially as that difference is directly related to the dynamics of hospitality. Such differences between sciences, much like those that separate ethnicities from each other, are never as absolute as their practitioners are wont to claim. But they are important. The length of time that anthropologists typically spend in the field, the processes of language learning and other varieties of cultural inculcation, and, above all, the enormous burden of personal responsibility that goes with the successful breaching of the walls of cultural intimacy are not only features of a rite of passage; they are, as befits a calling with such obviously ritualized techniques of research, the marks of a professional ethic that is as unique as it is pressing for the individual researcher.

This is not the place to explore further the outrageous bureaucratization of ethics that has in some places begun to straitjacket the discipline's basic methodology and that demands an ethical response. ${ }^{9}$ Here I would simply note that any system that removes the burden of responsibilityand the right to assume it-from the researchers themselves can hardly claim to be ethical except in the sense that policing can be called ethical; one suspects that in many cases the main objective is to protect the researchers' institutions from potentially expensive legal issues.

Hospitality provides but one example of the ethical dangers of projecting intimate, domestic engagements onto a much larger scale. The bureaucratization of ethical decision-making is another; it is analogous to the reduction of human experience to numbers and procedures justly pilloried by Grotti and Brightman. The ultimate indignity of death in the anonymizing sea, they point out in a significant replay of van Gennep's tripartite structure, is reversed through the ritual sequence of recovery, naming, and 
burial. By the same token, the reburial of the recuperated individual identities in the impersonal archive of bureaucratic documents and statistics is a violation and indeed a withdrawal of hospitality, an act of structural and ethical violence that Martello's evocation of Nazism and its victims, replete with echoes of Italian self-congratulation over not having been quite as bad as the Germans, is only partly successful in challenging.

Ultimately, what Sarah Wagner calls the "technology of remembering," cited here by Grotti and Brightman, can only work for those who are themselves operating with some sense of a real relationship with the departed. ${ }^{10}$ Anything else is theatre-which, to be sure, has its own ritual propensities (famously celebrated in the collaboration between Victor Turner and Richard Schechner ${ }^{11}$ ), but which, organized by state organizations, too easily works against the survivors' urge to refashion a real connection with those who are no longer alive and produces only empty ritualism.

Anthropologists have both a responsibility and a pressing professional need to resist such reductionism. Their ethical responsibility is an ineradicable debt to their informants, one that is straightforward enough conceptually, although paying that debt may sometimes be difficult to put into practice. The professional need comes from the devastating effects of audit culture on the way anthropologists can conduct their research-effects that occur not only through the misapplication of professional ethics already mentioned but also through the selective allocation of research funding. ${ }^{12}$ Here there is a direct parallel between the distortion of the hospitality paradigm in sociopolitical relations on the one hand and the distortion of ethnographic research triggered by current funding practices on the other. Unrestrained scaling up is capable of producing gross distortions of social relations, as well as of the ways in which we study those relations. This effect is especially evident in the structure of research funding in Europe, where not only are researchers often judged by their home institutions in terms of the cash they can pull in but it is also often the case that individual research of the highly personalized kind that we recognize as true ethnography is much harder to fund than enormous projects that allow little space for individual creativity in the field and rest on expectations of a high degree of predictability. Research with migrants and other precarious populations requires a delicacy of approach that fares poorly when funding is directed to self-styled experts with little prior cultural and linguistic knowledge either of the host countries or of the migrants' own cultural origins. ${ }^{13}$ 
In tying research to the objectivist goal of predictability, surely a gross distortion of the inchoate realities of human experience, this structure is intended to "responsibilize" researchers to perform according to narrowly conceived contractual arrangements while effectively removing from them any semblance of responsibility to ethnographic research - that is, to the capacity to respond creatively to field situations rather than following a narrowly prearranged line of inquiry with usually quite unsurprising results. In the terms I am laying out in this essay, this structure distorts the ritual of progressive discovery that lies at the core of anthropology's distinctive methodology, substituting, as Grotti and Brightman acutely note, the aridity of formal assessment for the rich revelations brought by a selfconsciously applied ritual sequencing of our work. It does so by upscaling research so that the domesticity of the ethnographic encounter risks becoming a tragically weakened metaphor for social-science methods answerable only to the voracious demands of audit culture. Those demands are for large-scale research that sacrifices the risky intimacy of the true ethnographic encounter for safely countable, reassuringly numerous, and superficially verifiable data. The authors of these papers have, by contrast, set an example of both feasibility and insight. Their work strengthens the argument for genuinely ethnographic research-research, that is, conducted on an intimate scale and entailing intense and protracted engagement with the social actors on whom it focuses - at a time when such work is threatened by the allure of large numbers and massive organizational structures.

The first port of call is logically the question of how the analysis of hospitality can move beyond the stereotype of Mediterranean identity. In this regard, Chiara Quagliariello is gloriously unequivocal. Hospitality to foreigners, she says, "has nothing to do with the notion that hospitality is part of the cultural values of the Mediterranean area." In this, she instantiates Brightman and Grotti's declaration that the authors of this volume "make no attempt to define a distinctive Mediterranean hospitality" but instead examine regimes and scalar transformations of hospitality in what happen to be circum-Mediterranean states. But the risk of falling prey to cultural essentialism remains part of what such scalar acrobatics entail. Quagliariello is thus undoubtedly correct in claiming that the provision of hospitality to foreigners does not demonstrate that hospitality is a typically Mediterranean feature; but Lampedusans do claim it as a typically Lampedusan virtue. Hospitality is, after all, an assertion of moral and social superiority in many parts of the world. Its distribution as a cultural 
trait is therefore unlikely to be restricted to any one geographical area; but, by the same token, it will be claimed as a distinctive moral property by virtually any social entity that recognizes it as a virtue in the first place. Every community I have visited, even one that had me unceremoniously deported by the Greek military regime in 1974, made extravagant claims about its own hospitality, often with the clear aim of demeaning nearby communities by comparison. And what goes for single communities goes equally, with minor variations, for districts, provinces, and even nation-states.

This is segmentary logic in action, and it becomes decidedly more aggressive as it moves to a more inclusive scale. Countries can each safely claim to be the most hospitable of all, knowing that other countries are anxious for them to keep the unwelcome visitors and largely care not one whit whether such ersatz hospitality entails active mistreatment or simple neglect of the so-called guests. This has been the burden borne by the southern European nations as a result of the Dublin Regulation whereby they were essentially forced to act as the other countries' border guards. Ethnography can (and here does) lead to a complex understanding of the violence conducted, not only against the bodies of the migrants but also against the sensibilities and values of local people who already have some experience of offering the migrants their local version of hospitality. Quagliariello's account reveals some variation in locals' views about the most appropriate ways of treating the foreigners. This may reflect a measure of competitive concern with reputation-a feature of small communities around the world, not only in the circum-Mediterranean area.

Quagliariello's nuanced account is especially valuable because, while she trenchantly dismisses the old spectre of a Mediterranean culture area, which often threatens to reappear in the thinnest of disguises, she also shows that it is based on some of the same totalizing logic as we see in the politics of border policing, Mediterranean solidarity, and resurgent ethnonationalism-hence my earlier remark about the danger of an emergent methodological nationalism but on a larger scale. Our methods are no less susceptible to scaling up than is local hospitality, and they face an analogous danger: that of absorption into large-scale survey analyses in which all traces of cultural nuance and individual agency have been suppressed. Even in anthropology, there is a risk of over-generalization. Moreover, in communities where a measure of self-regard is understood as a social virtue, the anonymity that we give individuals out of a concern for their privacy may inaccurately reinforce an impression of local homogeneity and, 
in the process, may also silence the agency of individuals desirous of recognition.

Quagliariello has managed to write an account that does reflect the nuances of factional horizontal disagreement as well as vertical disaffection from the views of the bureaucratic state. Her firmly grounded ethnographic analysis evokes a strikingly different Mediterranean than the old totalizing idea of a place solidly unified by the values of honor and shame. Instead, it accords with Ben-Yehoyada's view of the agonistic friendships between people from different Mediterranean locations as cousinage rather than fraternity, ${ }^{14}$ as she herself notes. Her incisive description of local reactions to the increased state control of "hospitality" also shows that the agonism of competitive hospitalities can be skewed vertically, up the scalar cliff as it were, allowing local people to reject the formal hospitality of the state as inferior to their own generosity.

Her analysis of this Italian site thus parallels recent discussions of the segmentary character of solidarity in Greece. ${ }^{15}$ Internally, too, the possibility for competing forms of hospitality appears in the way that Lampedusans have, for Quagliariello, fallen into categories that clearly express the tensions between solidarity and exclusion. Just as she can write about the Mediterranean without claiming it as a homogeneous area, she is also explicit in rejecting the old anthropological myth of homogeneous communities. Difference is the motor of interaction; complex relations dispel the convenient but empirically unsustainable illusion of total conformity at any level. Lampedusans are evidently able to distinguish among different groups of foreigners, albeit in perhaps rather stereotypical terms, and it would be interesting to know how far their apperception of the differences sharpened or weakened over time. Migrants do not constitute a homogeneous mass, although it is convenient for hostile authorities and unsympathetic journalists to act as though they did.

Both the competitive localism of the Lampedusans and their distrust, in varying degrees, of the state and its policies might superficially seem to reinstate that sense of a wider Mediterranean pattern that the early critiques of "Mediterraneanism" questioned. ${ }^{16}$ They do so, however, in a form that is both geographically more restricted and yet at the same time transcends the coastlines of the Mediterranean sea and that also allows for the play of significant internal variation at every level. As a unified entity, "the" Mediterranean is both a geographical datum and a political concept. It is not "a" culture; describing it as such simply (and simplistically) reinstates methodological nationalism at a higher scalar level ${ }^{17}$ and 
therefore almost certainly at an intellectually even more vacuous and destructive one.

That areal focus hangs, like evanescent traces of the smoke that men of this region so often display as evidence of their self-consciously Mediterranean masculinity (for local people can be the most egregious self-stereotypers of all), around all the essays collected here. It shrouds an implicit promise of new perspectives to appear as the smoke disperses. In some cases, this spectral areal focus is also useful in very direct, practical ways. There are cultural resonances among the various countries ringing the sea (men in most parts of the region do view smoking as a mark of masculinity, even though they ever more frequently express reservations about it) although these features may also change (on Crete, for example, I have found that in recent years some men have stopped smoking-along with heavy drinking and even in a few cases the massive consumption of fatty meat - as they have become increasingly careful of their health). That resonance has never been in serious doubt and was not put into question even by the most severe of the early critiques of Mediterraneanism, including my own.

There are also hints in these pages, however, of a more pervasive and interesting sense of mutual recognition, a form of semiosis that requires serious consideration for two good reasons: first, because it provides a much more nuanced pathway to understanding both intra- and extraMediterranean forms of cultural communication; and second, because it promises some useful methodological advances. From the complex (and internally contradictory) political implications of recalling the proximity of a fascist site during a memorial to migrants lost at sea, to the silent gestural communication between an ethnographer and social actors with whom she has no common language, these essays display and analyze telling moments of nuance, a word nicely glossed in Italian as sfumature-the things that fade like the dissipating smoke from a too aggressive confrontation of their presence. Much ethnography consists in catching those wisps before they dissipate altogether.

The sfumature adumbrated here suggests ways in which common cultural ground may transcend the more obvious differences that divide the many languages spoken in the area without pushing us toward a totalizing reductionism. Cynthia Malakasis' research, for example, was primarily focused on the Greek caregivers and their administrative support staff. As she persuasively argues, however, the political dynamics of hospitality infuse the maternity wards despite the scalar difference between those 
spaces of officially provided medical care and the domestic arena of the private home. One may wonder how the foreign women who were the patients, many of them from societies whose values overlap significantly with those reported from Greece, understood the gestures that Malakasis interprets from a knowledgeable Greek perspective; yet-and this is the core point-they clearly did indeed understand them, at least to some extent.

In the same way, I found myself wondering whether Quagliariello's Lampedusan informants felt some measure of kinship—cousinage?-with earlier arrivals from North Africa because of already existing traces of language contact in the local dialect, or of lingua franca in the everyday speech of both sides. That is not something to which we are ever likely to be able to give a definite answer, but any hint that such commonalities were noticed during interaction might point to such a historical grounding of mutual cultural resonance. The fact that some elements of cultural communication cannot be demonstrated except on the basis of circumstantial evidence-that they are unprovable in an objectivist sense-does not mean that they are unimportant. Quite to the contrary, such traces of commonality may be all the more durable for their resistance to easy identification. Moreover, the state's expropriation of territorial space for its sequestration of migrants and of the right even to interact with the migrants ruptured the very possibility of such discrete familiarity, making a mockery of official claims to be practicing anything Lampedusans or the migrants could recognize as true hospitality. Yet such familiarity, or mutual recognition, may have made the earlier pattern of locally provided shelter a potential link with similar interactions during the still more distant past.

In similar vein, Malakasis' convincing demonstration of communication that did not require the mediation of language leads me to wonder about the implications of the hospitality metaphor for the two sides of these sometimes uncomfortable cultural transactions. Were gesticulations of a kindness that was also a form of social control imbued with similar implications in (say) Syria and Greece, and were they therefore comprehensible, at least at a subconscious level, in the same terms? How would we know? What we need is something akin to a Benvenistean etymological genealogy for gesture and posture-not as a demonstration of continuity with a classical past, as in the celebrated work of the nineteenth-century scholar Andrea de Jorio ${ }^{18}$ but as evidence for commonalities that reverberate across space as well as time. Such a genealogy would be very difficult to trace. Even leaving aside the multiple languages that a researcher would 
need to master, itself a difficult goal in these days of restricted (and restrictive) funding, the links between language and other forms of social semiosis are not straightforward. Nevertheless, I suggest, in this linkage lies a potentially exciting new project that would shed critical light on both the realities and the stereotypes that infuse attempts to generalize about the Mediterranean in cultural terms.

Although that larger project might be very difficult to achieve, the traces of shared understandings are often quite palpable in the present time. In a plea to resuscitate the hospitality metaphor in situations of the kind she describes, Malakasis shows very clearly that both sets of social actors, midwives and migrants, did indeed share some measure of understanding of the metaphor of hospitality and that both sides understood the metaphor as not solely limited to the state's official rhetoric. We do not have to be madly Mediterraneanist to see that centuries of contact have produced some area of mutual intelligibility, possibly even to the point where gesture, although noticeably different from country to country in specific details, nevertheless also does afford a generic sense of connectedness. Indeed, such reciprocities might perhaps have served, as in BenYehoyada's accounts of Tunisian-Sicilian encounters, to revive the ghosts of an older age: more sfumature, more traces of convivial smoke shared in the agonistic amity, the jesting and jousting, of boats and cafés and brothels.

The chapters in this volume focus on hosts rather than guests and wisely so; the authors have opted to work in areas of their own unquestionable competence. This is a more productive approach than we see in so much of the hastily mounted investigation of the dynamics of migration. As Heath Cabot has noted, too many of the self-appointed migration experts who inflicted themselves on Greece, for example, spoke neither Greek nor any of the migrants' languages, but they also lacked the awareness of intercultural engagement that Malakasis implicitly (but persuasively) opposes to the cultural dissonance (usually in the form of racism) too often assumed rather than critically examined in migration studies. ${ }^{19}$ This is not to say that the racism does not exist-it unquestionably does-but rather to underscore the often subtly muted instances of real, effective communication that can and often does inspire a very different attitude to migrants on the part of host communities and even institutions.

Ethnographic research has a temporal dimension, as does hospitality. Indeed, much as rituals consist of a series of nesting boxes or Russian dolls, all (always as in van Gennep's schema) equally structured in triune 
form, acts of hospitality reproduce in miniature the longer-term relationships on which ethnography depends, and brings to a sharper focus the ritual features of entering the field from outside, transitioning to partial membership, and ultimate acceptance that is the fundamental pattern of virtually all serious in situ field research. As researchers try to make sense of the bewildering array of cultural differences (but also the equally striking similarities) among the migrants and their hosts, one methodological step that could conceivably shed a great deal of light on the intercultural dynamics would be the reflexive recording of the researchers' own difficulties and progress in various areas of cultural competence including-but not limited to-language. In a way, this is something all ethnographers do as a matter of course, but doing it with deliberate thoroughness amid all the complexities of intercultural engagement produced by migration could generate genuinely novel insights into the nature of communication, its failures, and its sometimes unexpected successes. Malakasis' insightful and self-aware retention of the domestic hospitality model, for example, suggests exciting possibilities for such an approach.

Malakasis' empathetic reconstruction of the Syrian patient's visual interaction with her, an interaction that seems all the more meaningful in the absence of verbal exchange ("interpretation that exceeded the linguistic," in her genial phrase), suggests that such a methodology might be a notable source of insight into how the structure of hospitality mediates cultural contact-more so, perhaps, than would be achieved by arriving with full proficiency in the patients' language from the start. Malakasis, although working primarily with Greek midwives, did in fact, in the course of her interactions with their patients, pick up a few words of Arabic. Her skill in so doing also allowed her to help newcomers among the Greek caregivers achieve greater rapport with their patients. Expanding that skill into a longer-term methodology might generate an unrivalled capacity to evaluate shifts in attitude, topics, and ease of communication across time, yielding rich methodological rewards of more general applicability.

Malakasis' sensitivity to nuance emerges clearly in the incident in which a midwife reacts angrily to being called a nurse. Not only does Malakasis allow her readers to learn from her unintentional mistake (most good ethnography results from the solecisms we inadvertently commit in the field), but she thereby strengthens the case for treating the hospitality metaphor as useful at this scalar level. Perhaps to an outsider, the hospital would not seem like an exact extension of a home, raising questions about the relevance of talking about hospitality, but the point here is precisely that it was 
the informant herself who chose to make an issue of what she saw as a violation of her professional identity and the sovereignty of her calling. As a result, the midwife also proactively moved to defend the cultural intimacy - the private inner core of a supposedly sovereign structure ${ }^{20}$ - of her profession and her country alike. Her action reproduces the logic of hospitality, albeit with a more obviously aggressive intent. Like hospitality itself, it both reveals and defends that inner core. Malakasis' evident discomfort with revealing such inner confessions of weakness typifies the dilemma of all anthropologists, whose métier is to explore the realms of cultural intimacy-since otherwise they would simply be mouthing the official perspectives already fully available to outsiders-but whose ethical commitment is to avoid potential harm to their informants, in this case by embarrassing them through the revelation of professional intimacies.

The responsibilities of the ethnographer, like those of any guest, are precisely to respect the sovereignty-limited but usually well-understood by all parties - of the host community, be that community a professional group, a village, or a bureaucratic institution. But the claim to sovereignty, like the obligations incurred by the gift in Mauss' famous account, should be discreet and indirect; when it becomes too blunt, a risk particularly triggered by scaling it up too far and too fast, it morphs into abusive power play. By connecting hospitality to sovereignty, Malakasis thus explains what she calls the "slackness" of the hospitality metaphor. The less the behavior of the self-appointed hosts resembles the local understanding of hospitality, the more it exposes their real intentions.

In this spirit, Quagliariello documents the tension between generosity to migrants and resentment over the state's arrogation to itself of the role of collective host-a role, moreover, that excludes the Lampedusans from what they consider their native territory and thereby rips the veil away from the invasive practices of state policing. This is structural violence at work: the sovereignty of local people is abruptly usurped by an impersonal force that in their eyes has no claim on the right to offer hospitality and is thus understood as invasive. Malakasis' slackness metaphor is especially apt here: the link between metaphor and referent is weakened by abuse. The rituals of hospitality belong with the sovereign host. When the bureaucratic ethnonational state attempts to arrogate those rituals to itself, it breaks and disrupts them, fatally destroying their generative power to sustain social relations and rendering them a limp and emasculated imitation of the originals: ritus interruptus. 
Bureaucracy itself entails a great deal of ritualistic activity, but its obsession with static categories and borders does not accommodate the modular flexibility of true rites of passage. Just as the nation-state attempts to suppress the evidence of temporal wear and tear, so, too, its bureaucracies airbrush the corrosions of time and the weaknesses and provisionality of territorial borders. Methodological nationalism often leads us to suppose, erroneously, that sovereignty is a matter of fixed borders enclosing welldefined spaces. Nothing could be further from the truth. Not only does it move between very different scalar versions of an imagined or claimed territory, but it is also a shape-shifter with a temporal trajectory that allows us to identify its unstable incarnations. An inspection of the history of Poland's borders over four centuries, for example, would dispel any illusion of stability, let alone permanence. All rituals involve some sort of passage, as Ardener's lapidary remark suggests, and this means that the shape of the eternal present is in reality a constantly changing reminder of the ephemerality of even the most powerful states. Shelley's poem Ozymandias is not only a reminder of the mortality of rulers; it is a reminder of the mortality of the institutions in their charge. ${ }^{21}$

But what kind of passage do the ritual structures of bureaucratic maintenance mark, and to what extent can we predict what they will produce? Nation-states, while insisting on the permanence and inflexibility of their own borders, are actively reshaping other zones of sovereignty, including many that are internal to their own territories. In pointing out this lability in a recent review of the tangled situation on the island of Lesbos, Efthymios Papataxiarchis reminds us that, in effect, nation-states-which claim to be epitomes of geopolitical stability - are allowing and even encouraging spatial mutations of sovereignty. ${ }^{22}$ Bureaucracies are ritualistic, to be sure, but experience teaches us that their ritual aspects do not necessarily produce predictable outcomes, and unpredictability may even be the goal of regimes intent on pushing migrant populations back from their own borders and maintaining them in a state of debilitating uncertainty as a warning to the imagined hordes of others awaiting their chance to enter European space. ${ }^{23}$

A ritual model for thinking about these phenomena should function, not as a means of foreclosing debate or imposing a formal schema on a wildly complex situation, and certainly not out of respect for an outdated anthropological convention, but, to the contrary, as a way of seeing where acts purporting to be forms of hospitality go off track, falling by the wayside of their own claimed intentions. It is not anthropologists, after all, 
who have scaled hospitality up in the first place; it was the migration industry, acting with motives even less admirable than those of the hotel trade's banalization of a human relationship in the so-called hospitality industry. Adopting the concept of the rite of passage as a heuristic device exposes the flaws in the metaphor-and, more to the point, the disingenuous attitudes and dishonest intentions behind its use. By plotting the incantatory evocation of hospitality through the multiple official manipulations of time and space, we stand at least some chance of understanding and tracking the shape-changing sovereignties, the inhuman migration regimes, within which real people-migrants and local hosts alike-are attempting to stabilize lives disordered, dismantled, and dismembered through, in many cases, no fault of their own.

\section{Notes}

1. I heard Ardener articulate this incisive phrase when I was a graduate student at Oxford (1972-76), but do not know of its appearance in his published work. See also Herzfeld (2009: 183). On rites of passage, see van Gennep (1960).

2. Lévi-Strauss (1974). On the structure of the book, see Herzfeld (1991).

3. Conversely, the passage out from ethnographic intimacy to incorporation in the world of scholarly publication can be as painful, and require as many lonely and difficult ethical decisions, as the initial rite of separation from home and the traumatic transition that is the fieldwork sojourn itself.

4. Ben-Yehoyada (2017).

5. Carter (1997) on Senegalese in Italy; Delaney (1990) on the Turkish migrants' home visits.

6. See especially Douglas (1966), Turner (1969).

7. Notably Rabinow (1977).

8. On Jordan, see Shryock (1997); on militant Buddhism in Sri Lanka, see especially Kapferer (1988).

9. I intend to address elsewhere the questionable ethics of bureaucratizing ethical standards in the social sciences and particularly in anthropology.

10. Wagner (2013: 633).

11. See especially Schechner (1985).

12. For a relatively recent assessment of the impact of audit culture, see Shore and Wright (2015).

13. This is the burden of Cabot's (2019) scathing assessment.

14. See Ben-Yehoyada (2014).

15. See Rakopoulos (2015) and the extended discussion in Herzfeld (2021). 
16. See Herzfeld (1984), de Pina Cabral (1989); and, for the more orthodox view, Davis (1977).

17. On methodological nationalism, see Wimmer and Glick Schiller (2002).

18. See Kendon (2000), a modern English-language annotated edition of de Jorio's magisterial account of Neapolitan gesture, with its attempts to establish connections between modern gesture and ancient statuary.

19. Cabot (2019) offers a trenchant critique of the current rash of migrant experts in Greece, but her critique, which is followed by a critical discussion with several commentators, could well be applied elsewhere.

20. See the analysis of cultural intimacy and extended discussion in Herzfeld (2016).

21. This, famously, is the central theme of Anderson's (1991) magisterial treatment of nationalism.

22. Papataxiarchis (2020).

23. On the ritualism of bureaucracy, see especially Handelman (1990), Herzfeld (1992).

\section{REFERENCES}

Anderson, Benedict R.O'.G. 1991. Imagined Communities: Reflections on the Origin and Spread of Nationalism. 2nd ed. London: Verso.

Ben-Yehoyada, Naor. 2014. Transnational Political Cosmology: A Central Mediterranean Example. Comparative Studies in Society and History 56: 870-901.

- 2017. The Mediterranean Incarnate: Region Formation between Sicily and Tunisia since World War II. Chicago: University of Chicago Press.

Cabot, Heath. 2019. The Business of Anthropology and the European Refugee Regime. American Ethnologist 46: 261-275.

Carter, Donald Martin. 1997. States of Grace: Senegalese in Italy and the New European Immigration. Minneapolis: University of Minnesota Press.

Davis, J. 1977. People of the Mediterranean: An Essay in Comparative Social Anthropology. London: Routledge \& Kegan Paul.

Delaney, Carol. 1990. The "Hajj": Sacred and Secular. American Ethnologist 17: 513-530.

de Pina-Cabral, João. 1989. The Mediterranean as a Category of Regional Comparison: A Critical View. Current Anthropology 30: 399-406.

Douglas, Mary. 1966. Purity and Danger: An Analysis of Concepts of Pollution and Taboo. London: Routledge \& Kegan Paul.

Handelman, Don. 1990. Models and Mirrors: Towards an Anthropology of Public Events. Cambridge: Cambridge University Press.

Herzfeld, Michael. 1984. The Horns of the Mediterraneanist Dilemma. American Ethnologist 11: 439-454. 
1991. Textual Forms and Social Formation in Evans-Pritchard and LéviStrauss. In Writing the Social Text: Poetics and Politics in Social Science Discourse, ed. Richard Harvey Brown, 53-70. New York: Aldine De Gruyter.

- 1992. The Social Production of Indifference: Exploring the Symbolic Roots of Western Bureaucracy. Oxford: Berg.

- 2009. Convictions, Paradoxes, and the Etymologies of Social Life: Embodied Rhetorics of Earnest Belief. In Culture and Rhetoric, ed. Ivo Strecker and Stephen Tyler, 182-206. Oxford: Berghahn.

- 2016. Cultural Intimacy: The Social Poetics and the Real Life of States, Societies, and Institutions. 3rd ed. New York: Routledge.

- 2021. Subversive Archaism: Troubling Traditionalists and the Politics of National Heritage. Durham, NC: Duke University Press.

Kapferer, Bruce. 1988. Legends of People, Myths of State: Violence, Intolerance, and Political Culture in Sri Lanka and Australia. Washington, DC: Smithsonian Institution Press.

Kendon, Adam, ed. and trans. 2000. A Translation of Andrea de Jorio's La Mimica degli Antichi Investigata nel Gestire Napoletano. Bloomington: Indiana University Press.

Lévi-Strauss, Claude. 1974. Tristes Tropiques. Translated by John and Doreen Weightman. New York: Athenaeum.

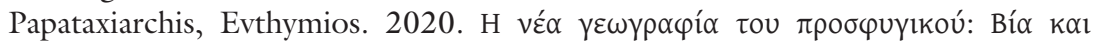

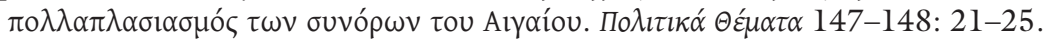

Rabinow, Paul. 1977. Reflections on Fieldwork in Morocco. Berkeley: University of California Press.

Rakopoulos, Theodoros. 2015. Solidarity Tensions: Informality and Sociality in the Greek Crisis. Social Analysis 59: 85-104.

Schechner, Richard. 1985. Between Theater and Anthropology. Philadelphia: University of Pennsylvania Press.

Shore, Cris, and Susan Wright. 2015. Audit Culture Revisited: Rankings, Ratings, and the Reassembling of Society. Current Anthropology 56: 421-444.

Shryock, Andrew. 1997. Nationalism and the Genealogical Imagination: Oral History and Textual Authority in Tribal Jordan. Berkeley: University of California Press.

Turner, Victor. 1969. The Ritual Process: Structure and Anti-structure. Chicago: Aldine.

van Gennep, Arnold. 1960[1909]. The Rites of Passage. Chicago: University of Chicago Press.

Wagner, Sarah. 2013. The Making and the Unmaking of an Unknown Soldier. Social Studies of Science 43: 631-656.

Wimmer, Andreas, and Nina Glick Schiller. 2002. Methodological Nationalism and Beyond: Nation-State Building, Migration and the Social Sciences. Global Networks 2: 301-134. 
Open Access This chapter is licensed under the terms of the Creative Commons Attribution 4.0 International License (http://creativecommons.org/licenses/ by $/ 4.0 /$ ), which permits use, sharing, adaptation, distribution and reproduction in any medium or format, as long as you give appropriate credit to the original author(s) and the source, provide a link to the Creative Commons licence and indicate if changes were made.

The images or other third party material in this chapter are included in the chapter's Creative Commons licence, unless indicated otherwise in a credit line to the material. If material is not included in the chapter's Creative Commons licence and your intended use is not permitted by statutory regulation or exceeds the permitted use, you will need to obtain permission directly from the copyright holder. 